\title{
On the Life Aesthetics of Aging People- Slowness Makes Life Beautiful
}

\author{
Kuei-Chiu Chang ${ }^{1}$, Mei-Ju Chou, ${ }^{2, *}$ \\ ${ }^{1}$ General Education Center, Department of Hospitality Management, Taiwan Shoufu University, Taiwan \\ ${ }^{2}$ Department of Early Childhood Education and Center for Teacher Education, National Pingtung University, Taiwan
}

Copyright $(\mathcal{C} 2015$ by authors, all rights reserved. Authors agree that this article remains permanently open access under the terms of the Creative Commons Attribution License 4.0 International License

\begin{abstract}
Taiwan has a rapid increase of elder population, which is supposed to double within the next 25 years. However, lifelong aesthetics learning for the elderly has not yet been fully developed. In the environment emphasizing on lifelong learning with increasing elder people, it is a crucial mission to design appropriate environment, curriculum, leisure activities for elder people in their later life. Under such premise, this study aims to explore various theories and try to evaluate and elaborate on aesthetics in diverse ways: Kant, Nietzsche and Hegel are the contributors to the theoretical perspectives on aesthetics. With the theories supporting the application of life aesthetics in the lives of seniors, this study finally concludes that aesthetics is crucial for the elderly as it improves life quality, physical, psychological health, social connectedness and continuous learning.
\end{abstract}

Keywords Life Aesthetics, Elder People, Social Connection, Physical Health, Psychological Health

\section{Introduction}

Taiwan has a rapid increase of aging population, which is supposed to double within the next 25 years. However, aesthetics lifelong learning for the elderly has not yet been fully developed. In the environment emphasizing on lifelong learning with increasing numbers of elder peoples, it is a crucial mission for us to design appropriate environment, curriculum, leisure activities for elder people in their later life (Leung, Lui \& Chi, 2005). Especially, due to the fact that in 2006, Taiwan Ministry of Education published "The White Paper of Elderly Education" has announced Taiwan has entered the lifelong learning century. In order to encounter the challenge derived from scientific achievement, globalization competition, internalization currency, and knowledge economy challenge, the series of elder people's service learning, food, clothing, housing, transportation, and community learning, Taiwan Ministry of Education established Active Aging Learning Resource Center to cooperate with township District Office, public libraries, community colleges, social welfare groups, community buildings, and etc. For more than 2000 years, the value of aesthetics education have been acknowledged and regarded as an influencing factor for development of healthy individual in Chinese culture. Further insight into the influence of aesthetics onto individual's lifelong learning has been proved by recent research. (Lim, 2005; Linda \& Margaret, 2012). The advancement of aesthetic awareness is related by the feel of environment, sound, color, taste, and sights. With the importance of aesthetic life philosophy, this study aims to relate the life aesthetics and elder people's leisure activities, curriculum, and life rhythm.

Aesthetics refers to a group of principles or values that relate to nature and the appreciation of beauty in art or environmental factors. It is a philosophical and a psychological process. Food, housing, clothing and transportation are some of the aesthetic characteristics that have a connection to the leisure activities of elder people, and everyday aesthetics focuses on the events that take place on a daily basis in an individual's life.

Apart from focusing on the fine arts of the natural environment, everyday aesthetics involves leisure activities such as modes of commuting, the undertakings at workplaces and other amusement factors. Life Aesthetics is imperative for seniors or the elder members of the society as the activities affect their social connection status, and psychological and physical health. Slowness is a major characteristic of the elderly and elicits the necessity for a motivating factor that would reverse the effects of old age (Brogan, 2013). By aesthetics, such individuals are enabled to overcome the adverse effects of old age and bring out functions in their environments and social lives.

\section{Theories of Life Aesthetics}

Various theories try to evaluate and elaborate on aesthetics in diverse ways. Those theories support the application of 
life aesthetics to life of the senior. All the theories concur on the fact that aesthetics is crucial for the elderly as it improves life quality and continuous learning, and Kant, Nietzsche and Hegel are the contributors to the theoretical perspectives on aesthetics.

\section{(I) Kant's Theory of Life Aesthetics}

Kant's prepositions are based on universality, imagination and intellectual abilities. To advance his perspective, Kant explains the problems of judging beauty of aesthetic factors such as art and the processes of deducing or coming up with personal tastes or preferences. Kant's critique of judgement tries to explain the reasons behind people's judgements and manner in which they consider certain things as beautiful and others as non-attractive. According to Kant, aesthetic judgments must have four distinctive features (Berger, 2011). First, aesthetic judgments are disinterested (McMahon, 2010); that is, people tend to take pleasure in certain things because they deem them as beautiful and rather than pleasurable. Second, those judgments are universal on basis of universality in Kant's theory. Under universality, it is expected that a particular judgement gains support from other people other than the individuals that formulate them.

Thirdly, Kant proposes that the judgements are necessary in the nature of human beings, so seniors also need aesthetics to live a comfortable life in old age. However, Kant asserts that necessity and universality are products of the human mental imagination and may not necessarily be the actual features of objects or pieces of art. His conclusion is that there is no objective feature that makes an object beautiful, since beauty is dependent on personal judgements and imagination.

People develop tastes or preferences founded on the aesthetic judgments making on certain issues. In addition, beauty is a feature that draws attention and people tend to make choices based on how beautiful a particular object is. According to Kant's theory, beauty does not have a purposive concept; instead, people attach some significance to it because of the imagination and judgments they have made.

Based on Kant's theory (McMahon, 2010), slowness among aging people is significant due to their personal judgments and ways of doing things. On basis of their life experiences of aesthetics appreciation, exploration, expression and creation, elder people can live comfortably by observing life aesthetics and avoiding negative judgments from other people. A person's judgment is treated as an independent opinion that may not be true, while appreciating forms of beauty and its own appearance is fundamental. Beauty's connection with art, nature and their social lives is consequently improved. Concerning Kant's Theory on seniors' life aesthetics arrangement in physical and psychological life, it focuses on the explanation of individuals' intellectual abilities and imaginations. Psychologically, seniors have unique tastes and preferences according to their personal cognitive imaginations or judgments, which constitute the psychological lives of seniors owing to aesthetics' influence on their reasoning and imaginative ways, while psychological conditions have a direct bearing on the physical life of seniors or other individuals.

\section{(II) Nietzsche's Theory of Aesthetics}

Nietzsche's assertion focuses on metaphysics and beauty. According to the theory, beauty is relative to and dependent on personal opinions. Human beings transform the world on foundation of their preferences, Nietzche's theory suggests that life has no meaning apart from the one human beings endow it with their preferences. In this respect, seniors are usually slow and less aggressive due to their old age. However, they also need to appreciate beauty and mold their environments subject to their preferences. In this sense, elder people make use of life aesthetics to achieve life goals. In addition, the theory suggests than humanity is the only beautiful thing with characteristics such as power, pride and courage. Nietzsche's theory deducts that the beauty of the world can only be justified when it becomes an aesthetic product.

Nietzsche defines art as a metaphysical complement that allows the transcendence of flora and fauna other than an imitation of nature (Byrne, 2012). The theory adds that art is a source of perfection and joy. Therefore, life is sustained by art's making it endurable and worth living. Conclusively, art maintains, enhances and affirms life. Nietzsche's theory (Adorno, 2013) supports the importance of aesthetics life in elder people's life values and quality. Regardless of the physical state, elder people require aspects like art that would enhance their lives and justify reasons for them to continue living.

Aging comes with various challenges. The most common one is the fact that body weakens and wrinkles appear on the skin. The characteristics of old age make people insecure about their appearance and they may pursue risky solutions such as plastic surgery. However, Nietzsche's theory merges beauty, art and metaphysical aspects of nature. Nature enables aging people to appreciate beauty in their own context in substitution with the perceptions of other people. In the end, such individuals are able to view themselves differently and appreciate the beauty that exists in their abilities. Art is one of the ways through which seniors can express their abilities to counter physical inabilities. Considering Nietzsche's Theory on seniors' life aesthetics arrangement in physical and psychological life, elder people undergo various physical changes as they grow old. Therefore, beauty and metaphysics bring up the aspects of physical looks and psychological satisfaction. According to Nietzsche, beauty is a product of aesthetics. Therefore, the aesthetic lives of seniors gives them confidence in the way they look and are able to define beauty in their independent perspectives. On the other hand, metaphysics is based on art which provides seniors an opportunity to engage in useful excursions that would generate psychological serenity for participation in what they love. 


\section{(III) Hegel's Theory of Aesthetics}

Hegel's theory bases its facts on the mind and enlightenment or Bildung (Kedney, 2011). Contrary to Kant's theory, Hegel's claim applies a more precise and extensive focus on beauty and art, and his philosophy analyses the institutions required if humanity, in this case, spirit, is to be self-determining and free. Such institutions include educational facilities, family and the state. At this point, the theory reiterates the imperativeness of lifelong education, and the elderly are encouraged to engage in educational processes throughout their lives to enhance their spirit and social connection.

For Hegel, art is figurative. The role of art is to express freedom in the correct context, which is fulfilled by the expression of freedom of spirit in its sanctified form without the normal life contingencies. For instance, old age is a life contingency but it would not hinder the quality and effects of art. The ideal freedom expressed through art constitutes beauty, which is fundamental in the study of life aesthetics (Comay, 2014).

According to Hegel's assumptions, he is of the opinion that his perception on art is both normative and descriptive. He perceives his account on art gives a description of the principal features of the exquisite works of art attributable to the Western tradition. Elder people are slow, but they could still engage in art and obtain satisfaction and relevance, since contented with oneself is imperative for appropriate psychological health.

Beauty and appearance are major components of aesthetics, and that is why Hegel presupposed that formal beauty is found in nature. Nevertheless, true aspects of beauty are evident in artistic works only. Human beings in an expression of their cognitive thoughts and creativity create beauty of art. In this regard, the elderly may not be able to engage in rigorous physical activities, and they can use art to express their mental thoughts, making themselves useful other than a burden to others.

However, according to Hegel's theory, beauty is not limited to the physical form, instead, it also takes content into account, which is one of Hegel's most controversial ideologies. The content referred by Hegel is freedom of spirit as well as serenity. Therefore, according to the theory, the incarnation the freedom of spirit is a visible expression that can be seen throughout art.

Bidung is defined according to Hegel's perspectives on the spiritual aspect. The aesthetic power of Bidung could arouse older people's confidence and autonomy, and it could also be a source of motivation for the elderly enabling them to make relevant reflections and change their attitudes towards life and friends. Such actions demonstrate the fundamental elements of the philosophical view of Bidung, including feeling, acting, thinking and wishing. Such processes initiate recreational and educational activities considerate of both individual and social ethics. When the senior or elder individuals change their attitudes and incline their daily activities towards better philosophical practices, they could achieve an improved physical and psychological health. Considering Hegel's theory on seniors' life aesthetics arrangement in physical and psychological life, Hegel explained that life aesthetics focuses on psychological factors and enlightenment, suggesting that art is an expression of the freedom of spirit. Psychologically, seniors are free to express their feelings, emotions and creativity through art. In the context of physical life, Kant's theory suggests that aesthetics initiate a change in attitude towards life in seniors. Subsequently, seniors are able to tailor their lives to accommodate aesthetic practices both psychologically and physically healthy.

\section{The Application of Life Aesthetics to Seniors' Daily life}

Life aesthetics shapes the manner in which old individuals behave and engage the challenges they face. The adoption of life aesthetics by the elderly assists them fitting into the society and finding the activities that interest them and in which they can actively engage. As a result, seniors can fit into the society, relate appropriately with others and even engage in lifelong education.

The focus of geriatric aesthetics is on the emotional and physical needs of elder persons. In geriatric aesthetics, health-conscious grooming in terms of clothing and hygiene is considered as vital as healthy diets. If an individual lacks either health-conscious grooming or healthy eating schedules, the resultant life quality diminishment will make elder age hazardous.

Geriatric aesthetics specialists are able to recognize psychological and physical conditions related to elder's mind and body. Therefore, the specialists respond appropriately without aggravating the condition already in existence and able to initiate the referral of the victim to a relevant advanced care institution (Miyahara, 2014).

Basic hygienic practices such as brushing teeth, maintaining neat hair nails and general grooming begin at a young age. Proper hygiene initiates the development of the somatic immune system. It should be noted that even as we grow old, we still require a strong immune system to survive through old age. Grooming enhances confidence in oneself and becomes more imperative as people grow older (Melchionne, 2013). Self-worth and beauty are integral aspects of aesthetics. Looking presentable results to an enhanced sense of self-importance and promotes both physical and mental health.

Other aesthetic aspects such as painting, building a house and writing a book gives individuals feeling of accomplishment, self-respect and pride. An enhanced self-worth gives life some sense in the case of senior individuals. Geriatric aesthetics is a specialty field of practice resulted from the rising population of elder adults in the global demographic systems. The profession provides a link between the aesthetic changes that are paramount when an individual ages and their relationship with old age (Smuts, 2013). 
(I) Positive Relationship between Life Aesthetics and the Physical Health of Seniors

As human grows up, the body systems become more complex and are fully mature at adulthood. Similarly, as an individual grows old, so does the body. Physical fragility and weakening of the body causes somatic strains. Some of the victims may become partially inactive and require assistance from younger individuals for instance when they want to move (Perniola, Verdicchio \& Silverman, 2012). Therefore, elder people require a method that they can use to overcome such effects, and this proves that Life aesthetics may be the answer to physical strains and disorders among the old population.

Physical health conditions are common when body parts age and become less functional. Elder people may find it difficult to move and engage in daily activities. In this regard, life aesthetic practices engaged in physical activities and interesting art excursions keep old adults agile (Pan, 2013). Additionally, physical health care through geriatric aesthetics assists in maintaining appropriate wellbeing and fitness. For instance, skin care is imperative because it expresses a lot about an individual's appearance and has a direct effect on how aging people rate their self-worth (Sampsel, 2014).

Living conditions or housing also constitutes life aesthetics. Elder people are fragile and should live in geographical areas free of health hazards. Architectural designs should also be considerate of the fact that most of the elderly individuals are physically less mobile or may not be able to move at all. Housing plans should be formulated in a manner that favors easy mobility of old persons (Shimamura $\&$ Palmer, 2011). Transport is also another area of concern in the discussion of life aesthetics in relation to old adults. When commuting, elder people should consider their physical health and use favorable modes of transport. And, when moving over short distances, walking would be desirable because it would make them physically fit and maintain the functionality of their locomotion structures.

Consequently, life aesthetics has a direct bearing on the physical health of elder individuals. Maintaining hygienic practices and physical exercises improve health conditions for elder people. Transportation may appear to be a simple mandatory day-to-day practice, but it also affects individuals' health. That is to say, if elder people ignore life aesthetics, they may fall captive to physical disabilities. For instance, reluctance to engage in physical activities may lead to the dysfunctionality of limbs, making the victims physically handicapped (Adorno, 2013).

(II) Positive Relationship between Life Aesthetics and the Psychological Health of Seniors

Psychological health is just as important as physical fitness. Mental strains occurring when an individual is aging can lead to psychiatric disorders. The serenity and sobriety of the mind is vital for elder adults, and psychological stress can lead into other complications like fatal heart conditions.
Life aesthetics assists aging people to avoid instances of psychological health complications (Miyahara, 2014).

From the provisions of geriatric aesthetics, life aesthetic aspects such as eating healthy food and grooming appropriately enhance the confidence of elder adults. It is part of human nature to care for our appearance and people's perceptions. Old adults may focus more on their appearance because of the undesirable physical aspects of aging age. However, it they worry too much about physical appearance, they may develop dysmorphic disorder, a psychological condition (Lee, 2011).

The disorder is common among patients with bulimia, anorexia as well as individuals undergoing plastic surgery for the belief that their appearance is not pleasant. Life aesthetics enable such individuals to maintain their bodily appearance and psychological health simultaneously. Consequently, psychological disorders resulted from low self-esteem among old adults is avoided (Goldie \& Schellekens, 2011).

\section{(III) The Positive Relationship between Life Aesthetics Cultivation Is and Seniors' Social Connectedness/Interpersonal Relationship/Interrelated Relationship}

Life aesthetics enhances the physical and mental health of elder adults and consequently improves their relationship with other people and the environment. Social connection is essential for the elderly, since they do not desire to be neglected by other members in the society. Taking part in substantive activities in the society makes elder individuals relevant and inculcates the sense of connection. Feeling important is a fundamental aspect of high self-esteem that elevates an individual's self-worth regardless of aging (Stecker, 2010).

Once elder adults are able to develop an appropriate level of social connection, they are able to establish good interrelationships within the society. Life aesthetics such as art brings different people together with interests in artistic designs. In this way, art initiates social relationships between people with similar interests. When aging people engage in art or nature excursions, they could meet diverse people with whom they could relate and socialize with (Kreitman, 2011).

Family relationships amongst elder individuals, children, grandchildren, relatives and even friends are crucial. Life aesthetics plays a major role in enhancing relationships within families. Engaging is leisure activities together enhances family bonds and integrates elder individuals into the family setting as they a role to play. Family attitudes have a direct effect on the lives of the elderly adults. Therefore, family ties are an imperative aspect of life aesthetics with regard to the elderly individuals (Kosnoski, 2010).

Consequently, life aesthetics are imperative for maintenance of appropriate health conditions for elder adults both physically and psychologically. Engagement of old individuals in physical and leisure activities enables them to live healthy lives and initiate social interrelationships with others and nature. For instance, the friendly warmth around 
traditional farmers elevates life aesthetics among the old. Aesthetic sensibility and creativity and the creation of an appropriate community for older people to live in, are also elevated (Ugwueze, 2011).

\section{(IV) Lifelong Education of Seniors}

In the normal setting, education is for the young individuals. However, life aesthetics enables integration of education and aging. Apart from art, leisure and physical activities, seniors can also engage in lifelong education to maintain their assertiveness and knowledge. As research shows, education in the latter years offsets high dependency rates and reduces the prevalence of disorders resulting from both physical and mental inactivity (Simpson, 2012).

Education in the later stages elicits happiness among those involved and widens their integration and connection to the society. Education of the seniors brings elder individuals with similar interests together (Titmus, 2014). Meanwhile, companionship in the course of learning leads to a healthier life because individuals are able to share their experiences with old age and learn from each other. For instance, most erlderly have retired from previous jobs and may miss the company of workmates, so the education of seniors remedies the loneliness that characterizes old age (Monahan \& Clancy, 2011).

\section{Conclusions}

Aesthetics is a philosophical and psychological concept that entails principles related to nature and the appreciation of beauty as an aspect of humanity. Life aesthetics involves activities such as leisure engagements, lifelong education, physical exercises, nature excursions and art. Life aesthetics is significantly vital for the elder members of the society. Most of the elderly individuals desire to live healthy lives and this motivates them to engage in life aesthetics (Stroud, 2011).

Various theorists have been formulating different definitions of aesthetics. Three examples of the perspectives have been formulated philosophers, namely Kant, Nietzsche and Hegel. Kant based his arguments on intellectuality, universality and the imaginative ability of the human minds, with assertion that humans are free to make independent judgements and deductions (Bashford, 2013). Nietzsche centered his theory on metaphysical aspects and beauty; and according to the theoretical preposition, beauty is relative. Lastly, Hegel's theory focuses on the cognitive mind and enlightenment of Bildung.

Life aesthetics affects the physical and psychological health status of old individuals. Physical activity and geriatric aesthetics reduces the incidence and prevalence rates of disorders related to aging issues. Education of seniors is also a notable aesthetic principle. By learning at the elder age re-integrates seniors into the society and develops their social connectedness and knowledge (Jarvis, 2010).

\section{REFERENCES}

[1] Adorno, T. W. (2013). Aesthetic theory. London: Bloomsbury Academic

[2] Bashford, B. (2013). Aestheticism, Pater, Literary Theory. English Literature in Transition, 1880-1920, 56(3), 406-410.

[3] Berger, D. (2011). Kant's Aesthetic Theory: The Beautiful and Agreeable. New York. A\&C Black.

[4] Brogan, J. (2013). American Literature's Aesthetic Dimension. College Literature, 40(1), 145-148.

[5] Byrne, R. (2012). Nietzsche's Aesthetics and Pauline Réage's Story of O. Papers on Language \& Literature, 48(2), 197-218.

[6] Comay, R. (2014). Defaced Statues: Idealism and Iconoclasm in Hegel's Aesthetics. October, (149), 123-142.

[7] Goldie, P., \& Schellekens, E. (2011). The aesthetic mind: Philosophy and psychology. Oxford [England: Oxford University Press.

[8] Jarvis, P. (2010). Adult Education and Lifelong Learning: Theory and Practice. New York. Routledge.

[9] Kedney, J. S. (2011). Hegel's Introductory Lectures on Aesthetics. Didireads.com Publishing.

[10] Kosnoski, J. (2010). John Dewey and the habits of ethical life: The aesthetics of political organizing in a liquid world. Lanham, Md: Lexington Books.

[11] Kreitman, N. (2011). Art as Orientation. Metaphilosophy, 42(5), 642-657. doi:10.1111/j.1467-9973.2011.01720.xdoi:10.1111/sjp.1204 4

[12] McMahon, J. (2010). The Classical Trinity and Kant's Aesthetic Formalism. Critical Horizons, 11(3), 419-441. doi:10.1558/crit.v11i3.419

[13] Melchionne, K. (2013). The Extraordinary in the Ordinary: The Aesthetics of Everyday Life. Journal of Aesthetics \& Art Criticism, 71(3), 296-298. doi:10.1111/jaac.12026_3

[14] Miyahara, K. (2014). Exploring Social Aesthetics: Aesthetic Appreciation as a Method for Qualitative Sociology and Social Research. International Journal of Japanese Sociology, 23(1), 63-79. doi:10.1111/ijjs.12025

[15] Monahan, Jerome \& Clancy, Joe. (May 17, 2011). Lifelong Learning is the Secret to Happiness in Old Age. The Guardian. Web. July 6, 2015. Accesses

http://www.theguardian.com/adult-learning/lifelong-learning -key-to-happiness

[16] Pan, H. (2013). Somaesthetics and Leisure: The Theory and Practice of Shusterman's Aesthetic Thoughts. (English). Tourism Tribune / Lvyou Xuekan, 28(9), 114-120. doi:10.3969/j.issn. 1002-5006.2013.09.013

[17] Perniola, M., Verdicchio, M., \& Silverman, H. J. (2012). 20th century aesthetics: Towards a theory of feeling. New York: Continuum.

[18] Sampsel, L. J. (2014). The Aesthetic Life of Cyril Scott. 
Notes, 71(2), 277-280.

[19] Shimamura, A. P., \& Palmer, S. E. (2011). Aesthetic science: Connecting minds, brains, and experience. Oxford: Oxford University Press.

[20] Simpson, Z. (2012). Life as art: Aesthetics and the creation of self. Lanham, Md: Lexington Books.

[21] Smuts, A. (2013). The Good Cause Account of the Meaning of Life. Southern Journal of Philosophy, 51(4), 536-562.

[22] Stecker, R. (2010). Aesthetics and the philosophy of art: An introduction. Lanham: Rowman \& Littlefield Publishers.

[23] Stroud, S. R. (2011). John Dewey and the artful life: Pragmatism, aesthetics, and morality. University Park, Pa: Pennsylvania State University Press.
[24] Titmus, C. J. (2014). Lifelong Education for Adults: An International Handbook. Burlington: Lee, V. (2011). The beautiful: An introduction to psychological aesthetics. Cambridge [u.a.: Cambridge Univ. Press. Elsevier Science.

[25] Ugwueze, U. L.-T. (2011). African culture, identity, and aesthetics: The igbo example. Bloomington, IN: AuthorHouse.

[26] Rioux, L., \& Werner, C. (2011). Residential satisfaction among aging people living in place. Journal of Environmental Psychology, 31(2), 158-169.

[27] Blakeborough, D. (2008). "Aging people are useless": Representations of aging on The Simpsons. Canadian Journal on Aging/La revue canadienne du vieillissement, 27(01), 57-67. 